\title{
Climate change impacts on rainfall erosivity and hillslope erosion in NSW
}

\author{
$\underline{\text { X. Yang }}{ }^{a}$, B. Yu ${ }^{\text {b }}$ and Q.G. Zhu ${ }^{c}$ \\ ${ }^{a}$ New South Wales Office of Environment and Heritage, PO Box 3720, Parramatta, NSW 2150, Australia. \\ ${ }^{b}$ School of Engineering, Griffith University, Queensland 4111, Australia. \\ ${ }^{c}$ Ecological Modelling Research Group, University of Technology, Sydney, NSW 2007, Australia. \\ Email: xihua.yang@environment.nsw.gov.au
}

\begin{abstract}
There are considerable seasonal and inter-annual changes in rainfall amount and intensity in South-East Australia (SEA), particularly in coastal New South Wales (NSW). Consequently, soil erosion rates may be expected to change in response to changes in the erosive power of rainfall or rainfall erosivity. Recently, the downscaled $10 \mathrm{~km}$ rainfall projections from New South Wales (NSW) and Australian Capital Territory (ACT) Regional Climate Modelling (NARCliM) project have become available for the SEA region for the baseline (1990-2009), near future (2020-2039) and far future (2060-2079) periods. The aim of this study was to model and assess the impacts of climate (rainfall) change on rainfall erosivity and hillslope erosion risk in SEA based on the NARCliM projections from all the 12 model member ensembles. Outcomes from this study are to assist the long-term climate change adaptation and regional planning such as NSW state planning regions (SPR).
\end{abstract}

A daily rainfall erosivity model has been specifically developed and applied to calculate monthly and annual rainfall erosivity values from the NARCliM projected daily rainfall data for the baseline and future periods. Monthly and annual hillslope erosion risks for the same periods were estimated using the Revised Universal Soil Loss Equation (RUSLE). Finer scale $(100 \mathrm{~m})$ surfaces of rainfall erosivity and hillslope erosion have been produced using spatial interpolation techniques. Automated scripts in a geographic information system (GIS) have been developed to calculate the time-series rainfall erosivity and hillslope erosion so that the processes of large quantity NARCliM data are realistic, repeatable and portable.

Adequate random sampling points (4991) were used to sample and assess the accuracy of the modelled rainfall erosivity from the NARCliM projections. The GIS modelled mean annual rainfall erosivity values from the NARCliM projected daily rainfall were compared with those calculated using the gridded daily rainfall data from Bureau of Meteorology for the baseline period (1990-2009). The overall coefficient of efficiency $\left(\mathrm{E}_{\mathrm{c}}\right)$ is $0.9753\left(\mathrm{R}^{2}=0.9762\right)$, and RMSE $13.2 \%$ or $143\left(\mathrm{MJ} \cdot \mathrm{mm} \cdot \mathrm{ha}^{-1} \cdot \mathrm{hr}^{-1} \cdot \mathrm{year}^{-1}\right)$ indicating the relative size of the error bars from the 1:1 line.

The modelled baseline rainfall erosivity in NSW varies from less than 300 on parts of western NSW to over 15,000 on parts of the North Coast, with a mean of $1112\left(\mathrm{MJ} \cdot \mathrm{mm} \cdot \mathrm{ha}^{-1} \cdot \mathrm{hr}^{-1}\right.$.year $\left.{ }^{-1}\right)$. Both rainfall erosivity and hillslope erosion risk are predicted to increase about $7 \%$ in the near future, and about $19 \%$ increase in the far future compared with the baseline period. The change is highly uneven in space and time, with the highest increase occurring in the Far-west SPR in autumn, with an increase about $22 \%$ in the near future and about $29 \%$ in the far future. The rainfall erosivity is generally higher in summer and lower in winter, with about 10 times difference between February (highest) and July (lowest).

Overall, the risk of soil erosion on NSW agricultural and plantation lands is expected to be steady, largely due to the flat topographic factor. The lands with "Intensive uses" will have high erosion risk due to the combined effect of terrain and rainfall erosivity. These 'hot-spot' erosion risk areas have been identified and mapped to assist decision makers to develop the best management practices.

Keywords: Rainfall erosivity, hillslope erosion, climate change, impact assessment, NARCliM 


\section{INTRODUCTION}

Climates in New South Wales (NSW) are highly variable, ranging from subtropical in the northeast part with summer-dominated rainfall to temperate climates with uniform or moderately winter rainfall in the southern part. The temporal and spatial variations in rainfall have enormous implications for soil conservation, food security, and natural resources management. One of the key climate drivers for soil erosion and land degradation is rainfall erosivity or R-factor as defined in the Revised Universal Soil Loss Equation (RUSLE, Renard et al. 1997).

Rainfall erosivity is largely a function of rainfall amount and peak rainfall intensity, and the R-factor, in unit MJ.mm.ha ${ }^{-1} \cdot \mathrm{hr}^{-1}$.year ${ }^{-1}$, is a multi-annual average index that measures rainfall's kinetic energy and intensity to describe the effect of rainfall on sheet and rill erosion (Renard et al. 1997). When factors other than rainfall are held constant, soil losses due to water erosion are directly proportional to the level of rainfall erosivity (Wischmeier and Smith 1978). When using the RUSLE, the R-factor is multiplied with other component factors relating to slope and slope-length (LS-factor), soil erodibility (K-factor), ground cover (C-factor) and soil conservation practices (P-factor) to predict the average annual soil loss per unit area.

Earlier work on rainfall erosivity in NSW was focused on the R-factor values calculated using pluviograph data at selected sites, and empirical relationships between the R-factor and rainfall intensity were used to map rainfall erosivity (Rosewell and Turner 1992). These isoerodent rainfall erosivity maps for NSW are static in nature, and unable to capture the seasonal and inter-annual variability in rainfall erosivity.

While a change in rainfall amount and intensity is expected to have significant effect on rainfall erosivity and soil erosion, the magnitude of the impact is not well quantified because of the non-linear nature of the relationship between rainfall amount and rainfall erosivity, and the extreme nature of large erosive events. Natural resource management targets can be more easily achieved if the soil erosion hazard and land degradation is well understood, and if the mean as well as extreme erosivity values are accurately mapped at a range of temporal and spatial scales. The high resolution R-factor maps, in both spatial and temporal contexts, can provide detailed information for climate (rainfall) impact assessment, and inform measurable and cost effective means in sheet erosion identification and rehabilitation.

A daily erosivity model has been developed and the required parameter values can be estimated from longterm climate averages or geographical attributes to allow efficient large scale erosion assessment ( $\mathrm{Yu}$ and Rosewell 1996; Yu 1998; Lu and Yu 2002). The technology has been widely used to estimate the magnitude and spatial distribution of soil erosion at a range of temporal and spatial scales ( $\mathrm{Lu}$ and $\mathrm{Yu} 2002 ; \mathrm{Lu}$ et al. 2003), and for assessment of the impact of projected future climates on soil erosion and catchment health in NSW (Yang et al. 2015). With the regional relationship for model parameters (Yu 1998; Lu and Yu 2002), rainfall erosivity can now be estimated with gridded daily rainfall data anywhere in Australia. The improved rainfall erosivity model (Yang and $\mathrm{Yu}$ 2015) may also have the potential to predict spatial and temporal changes of rainfall erosivity and soil erosion risk using future climate projections.

NSW and ACT Regional Climate Modelling (NARCliM) funded by NSW Office of Environment and Heritage $(\mathrm{OEH})$ is an initiative to produce regional climate projections for South-East Australia. 12 climate member ensembles were used to provide robust and unbiased projections that span the range of likely future changes in climate (Evans et al. 2014). A wide variety of climate variables have been made available at high temporal and spatial resolution for use in impacts and adaptation research including precipitation at daily and hourly steps which are the major input data in this study.

The aim of this study was to model and assess the impacts of climate (rainfall) change on rainfall erosivity and hillslope erosion across South-East Australia (SEA) based on simulations from the NARCliM projections, and produce finer scale (up to $100-\mathrm{m}$ resolution) time-series R-factor maps using spatial interpolation techniques. This report outlines the data and methods used to produce the time series rainfall erosivity maps for NSW and SEA, and the impact assessment of baseline and future rainfall on erosivity and hillslope erosion risk in the state planning regions (SPR) of NSW.

\section{DATA, STUDY AREA AND METHODS}

The dominant input data sets include: 1) NARCliM projected daily rainfall with bias correction for all 12 member ensembles from four Global Climate Models (GCM, CGCM 3.1, CSIRO mk3.0, ECHAM5, MIROC-medres 3.2) and three Regional Climate Models (RCM, R1, R2, R3) for all three time periods (1990-2009, 2020-2039, 2060-2079); 2) Gridded daily rainfall at $5 \mathrm{~km}$ spatial resolution from Bureau of Meteorology since 1900; 3) 1-second (about 30m) hydrologically corrected Digital Elevation Model (DEM- 
H) from GeoScience Australia; 4) NSW Great Soil Groups (GSG) map and Soil and Land Information System (SALIS) from OEH.

The NARCliM model domain is defined $21.669^{\circ}-39.749^{\circ} \mathrm{S}$ and $132.724^{\circ}-165.725^{\circ} \mathrm{E}$ which covers the SEA landmass area (Evans et al. 2014). There are 124 rainfall stations in SEA with pluviograph data available for model development and validation (Yang and Yu 2015). For statistical purposes, the spatial variation and comparisons are focused on NSW SPRs. Figure 1 shows the SEA (left) and the SPRs (right).

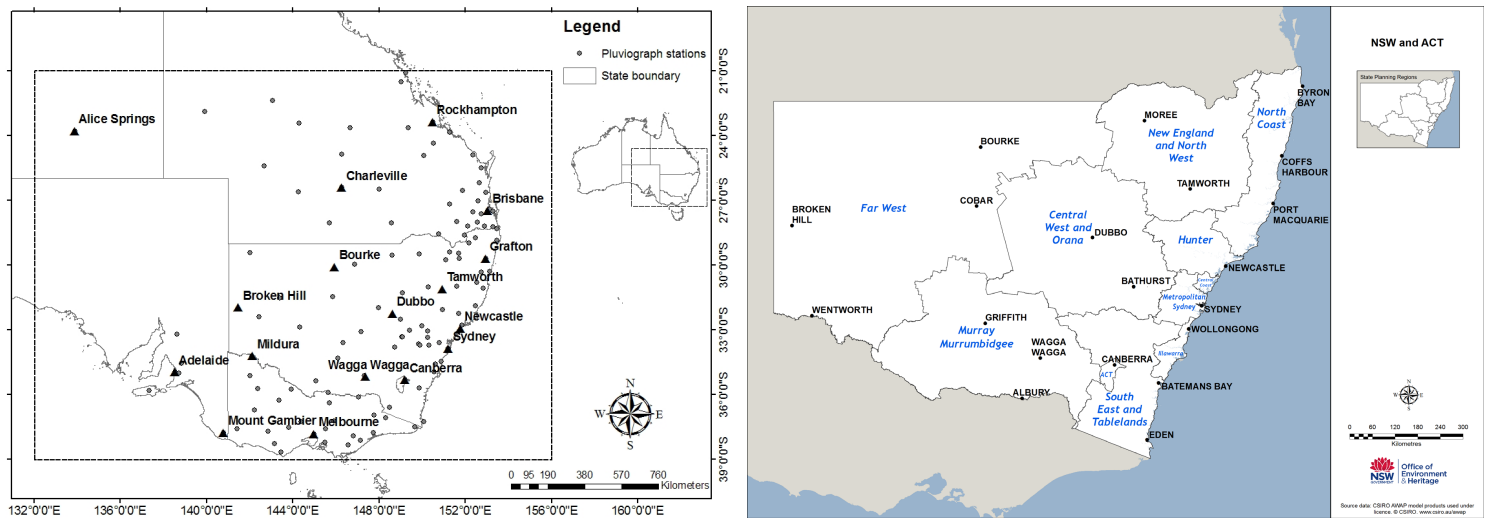

Figure 1. The South-East Australia (SEA) landmass area and the locations of rainfall pluviograph sites (left), and New South Wales state plan regions (right).

The daily rainfall erosivity model follows that of $\mathrm{Lu}$ and $\mathrm{Yu}$ (2002) with significant improvements on model parameters (Yang and Yu 2015). Briefly, the model to estimate the sum of storm's total kinetic energy and the peak 30-min (5 x 6-min) intensity (or rainfall erosivity index EI30) values for the month $j$ from daily rainfall amounts (in unit MJ.mm.ha- ${ }^{-1} \cdot \mathrm{hr}^{-1} \cdot \mathrm{month}^{-1}$ ) is based on

$$
\hat{E}_{j}=\alpha[1+\eta \cos (2 \pi f j-\omega)] \sum_{d=1}^{N} R_{d}^{\beta}
$$

where $R_{d}$ is the daily rainfall amount (mm/day), $N$ is the number of rain days in the month, and $\alpha, \beta, \eta$, and $\omega$ are model parameters. The model assumes a non-linear relationship between daily rainfall amount and daily rainfall erosivity (EI30) values via the parameter $\beta$. For the same amount of rainfall, however, rainfall erosivity can vary depending on the time of year and the location, especially the latitude and elevation. The remaining three parameters in Equation (1), namely $\alpha, \eta$, and $\omega$, were used in an attempt to capture these effects in a relatively parsimonious fashion. Details of these parameters and their calculation are presented in Yang and $\mathrm{Yu}(2015)$.

The monthly rainfall erosivity layers produced from Equation (1) were further used to estimate soil erosion risk (hillslope erosion for bare ground) based on RUSLE (Renard et al. 1997):

$$
A=R \times K \times L S \times C
$$

where $A$ is the predicted potential soil erosion risk (tonnes.ha-1.year ${ }^{-1}$ ), $R$ is rainfall erosivity factor, $K$ is the soil erodibility factor, $L S$ is the slope and steepness factor, $C$ is the cover and management factor $(C=1$ for bare soil). Note that the soil conservation practices (P-factor) were not considered in this work as the relevant future data are not available. The K-factor was prepared from the great soil group and LS-factor calculated from DEM-H (Yang 2015). Due to the large quantity of data sets, automated GIS scripts have been developed to process the daily rainfall data and calculated the time-series monthly and annual rainfall erosivity and hillslope erosion risk.

Model performance is measured by the coefficient of efficiency, $E_{c}$ (Nash and Sutcliffe 1970) as:

$$
E_{c}=1-\sum_{i=1}^{M}\left(y_{i}-\hat{y}_{i}\right)^{2} / \sum_{i=1}^{M}\left(y_{i}-\bar{y}\right)^{2}
$$

where $y_{i}$ and $\hat{y}_{i}$ are observed and modelled values, respectively; $\bar{y}$ is the average of observed values, and $\mathrm{M}$ is the sample size. Essentially, $E_{c}$ is an indicator of how close the scatters of predicted versus actual values are to the 1:1 line which can be considered as a measure of model efficiency for any other types of models. In addition, mean relative error (MRE), root mean squared error (RMSE) are also used for accuracy assessment. 


\section{RESULTS AND DISCUSSION}

\subsection{GIS Data Layers}

Based on the daily rainfall erosivity model as outlined above, we produced monthly and annual rainfall erosivity GIS layers (total 34,800) for entire NSW and SEA from the daily rainfall data for all 12 NARCliM essembles and three projection periods (1990-2009, 2020-2039, 2060-2079). Mean annual and seasonal rainfall erosivity and the changes were further calculated and spatially interpolated into fine spatial resolution (100 m) using Spline interpolation (Hutchinson 1998). The time-series rainfall erosivity data were further used to estimate hillslope erosion risk based on RUSLE (Equation 2), and the same sets of erosion risk layers (monthly and annual) have been produced for the same periods in NSW and SEA, plus spatial interpolation and calculation of multi-model and seasonal means (same as rainfall erosivity). Figure 2 shows the modelled mean annual rainfall erosivity and hillslope erosion risk for baseline and future periods.

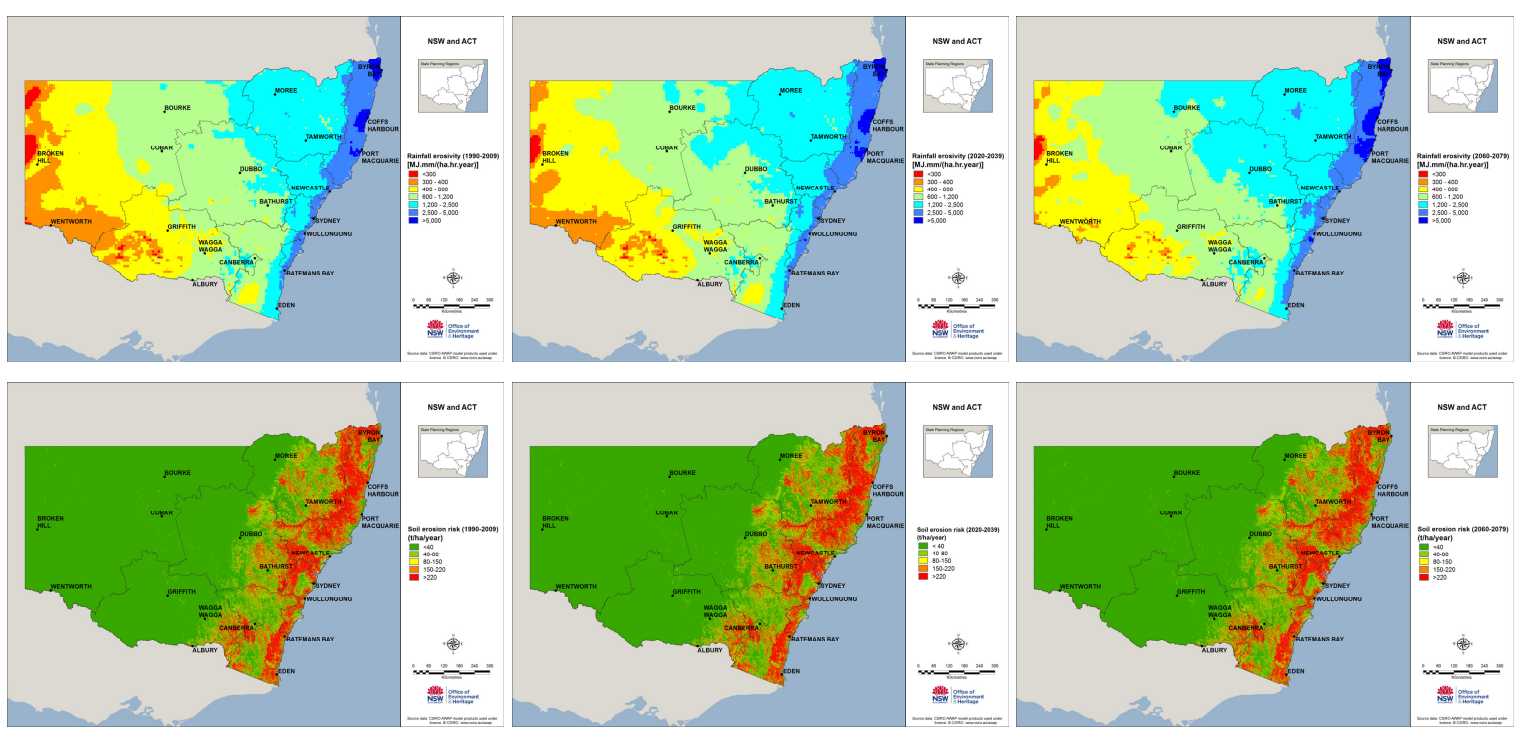

Figure 2. Modelled mean annual rainfall erosivity (top row) and mean annual hillslope erosion risk (bottom row) for baseline (left), near future (middle) and far future (right) periods.

\subsection{Accuracy Assessment}

The GIS modelled mean annual rainfall erosivity values using the NARCliM projected daily rainfall were compared with those calculated using the gridded daily rainfall data at $5-\mathrm{km}$ spatial resolution from Bureau of Meteorology (BoM) for the baseline period (1990-2009). The overall $E_{c}$ for the rainfall erosivity is 0.9753 $\left(\mathrm{R}^{2}=0.9762\right)$, overall bias is 0.9925 suggesting a slight under-estimation, and RMSE is $13.2 \%$ or 143 (MJ.mm.ha ${ }^{-1} \cdot \mathrm{hr}^{-1}$.year-1) indicating the relative size of the error bars from the 1:1 line (Figure 3, left). The seasonal patterns between the NARCliM and BoM data are also similar, both showing high rainfall erosivity in summer and low in winter (Figure 3, right).
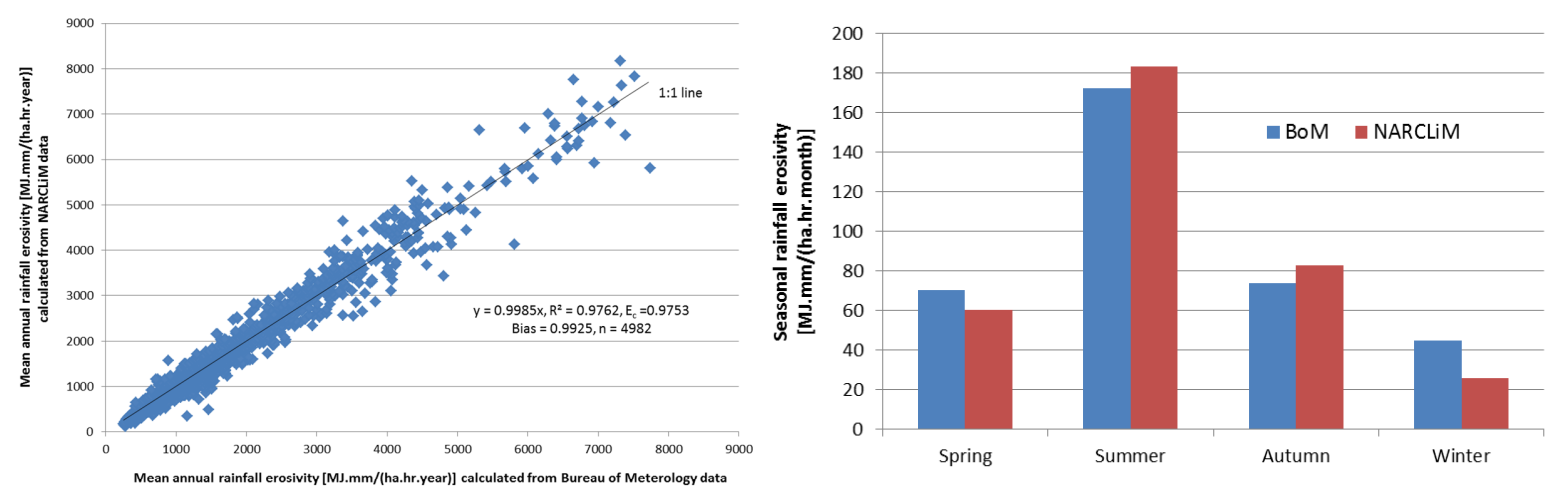

Figure 3. Comparison of mean annual rainfall erosivity calculated from NARCliM projections and BoM rainfall data (left) and their seasonal variations (right). 


\subsection{Future Changes in Rainfall Erosivity}

Compared with the baseline period (1990-2009), the mean annual rainfall erosivity in NSW is predicted to increase in the future. State-wide, there is about $7 \%$ increase in the near-future period (2020-2039) and about $19 \%$ increase in the far future period (2060-2079). Figure 4 shows the percent change (\%) of rainfall erosivity in the near-future and far-future periods across NSW.

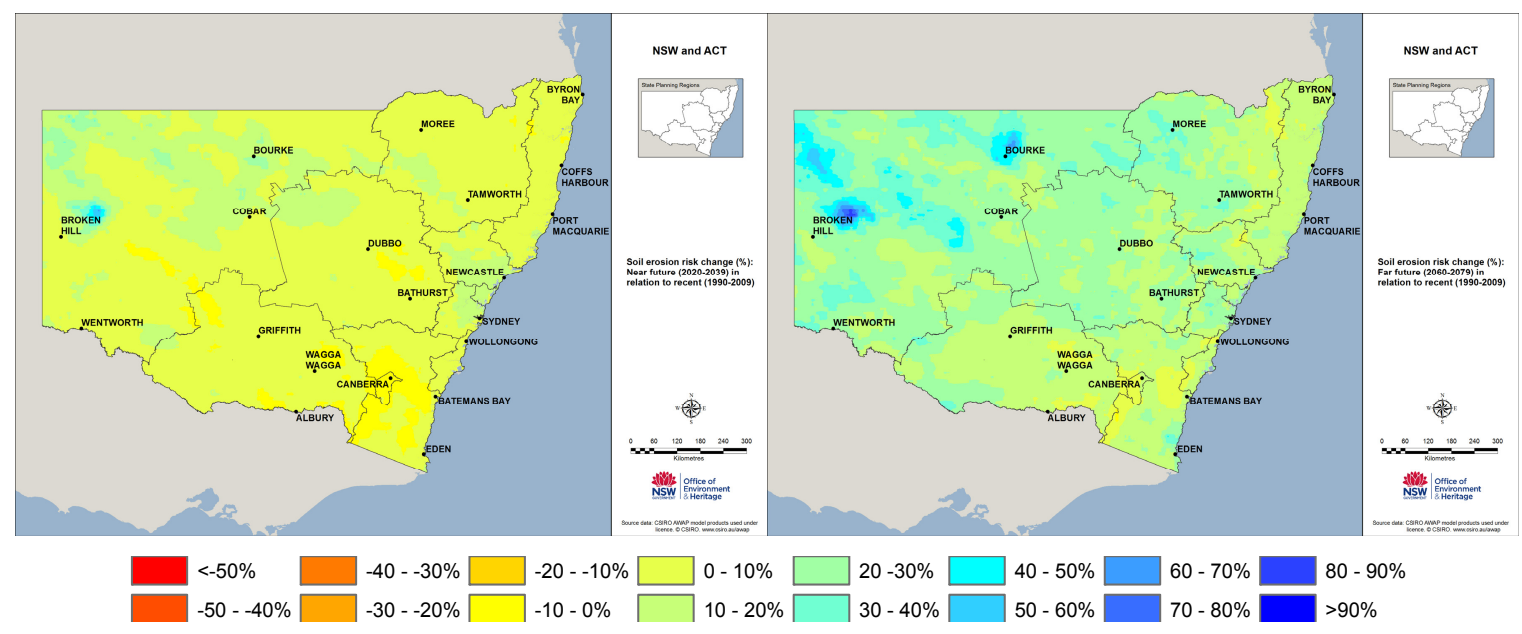

Figure 4. The percent change (\%) of rainfall erosivity in the near-future period (2020-2039, left) and the far future period (2060-2079, right) compared with the baseline period (1990-2009).

Future changes for each state plan region in relation to the baseline period are summarised in Table 1. Changes vary from $1.4 \%$ (South East and Tablelands) to $13.8 \%$ (Central Coast) in the near future, from $13.9 \%$ (Illawarra) to $27.5 \%$ (Far West). Higher erosivity is likely in coastal areas in the near future, with larger increases across the whole state in the far future.

Table 1. Mean annual rainfall erosivity (MJ.mm.ha $\left.\mathrm{a}^{-1} \cdot \mathrm{hr}^{-1} \cdot \mathrm{year}^{-1}\right)$ and their changes across NSW in the future periods (2020-2039 and 2060-2079).

\begin{tabular}{|l|c|c|c|c|c|}
\hline State Plan Region & Baseline & Near future & Far future & $\begin{array}{c}\text { Near future } \\
\text { change (\%) }\end{array}$ & $\begin{array}{c}\text { Far future } \\
\text { change (\%) }\end{array}$ \\
\hline Far West & 598 & 655 & 762 & 9.6 & 27.5 \\
\hline Murray Murrumbidgee & 568 & 585 & 665 & 3.0 & 17.0 \\
\hline South East and Tablelands & 1100 & 1116 & 1263 & 1.4 & 14.7 \\
\hline Illawarra & 2683 & 2775 & 3056 & 3.4 & 13.9 \\
\hline Central West and Orana & 1064 & 1125 & 1295 & 5.8 & 21.7 \\
\hline New England and North West & 1663 & 1754 & 2009 & 5.5 & 20.8 \\
\hline North Coast & 4043 & 4248 & 4647 & 5.1 & 15.0 \\
\hline Hunter & 1736 & 1923 & 2074 & 10.8 & 19.5 \\
\hline Central Coast & 2933 & 3339 & 3520 & 13.8 & 20.0 \\
\hline Metropolitan Sydney & 2075 & 2293 & 2523 & 10.5 & 21.6 \\
\hline New South Wales & $\mathbf{1 0 8 1}$ & $\mathbf{1 1 4 7}$ & $\mathbf{1 3 0 0}$ & $\mathbf{6 . 9}$ & $\mathbf{1 9 . 2}$ \\
\hline
\end{tabular}

\subsection{Seasonal Change}

Figure 5 shows the modelled mean monthly rainfall erosivity and the seasonal variation in the three periods from NARCliM projection. The seasonal variation is similar to the pattern of the baseline periods showing high rainfall erosivity in summer and low in winter, with about 10 times difference between February (highest) and July (lowest). But the seasonal changes are highly uneven and variable among the 12 member ensembles. The variations range from $-22.2 \%$ in spring to $105.3 \%$ in autumn for the near future period, and from $-33.7 \%$ in winter to $101.2 \%$ in autumn for the far future period.

In the near and far future, it's predicted that the rainfall erosivity will generally increase in all seasons (except slight decrease in the near future in spring and winter), particularly in autumn with an increase about $22 \%$ in the near future and about $29 \%$ in the far future. Rainfall erosivity in summer is also predicted to increase 
significantly, about $5 \%$ in the near future and $26 \%$ in far future. The information of rainfall erosivity seasonality can provide critical information for hillslope erosion control and development of best management practices.
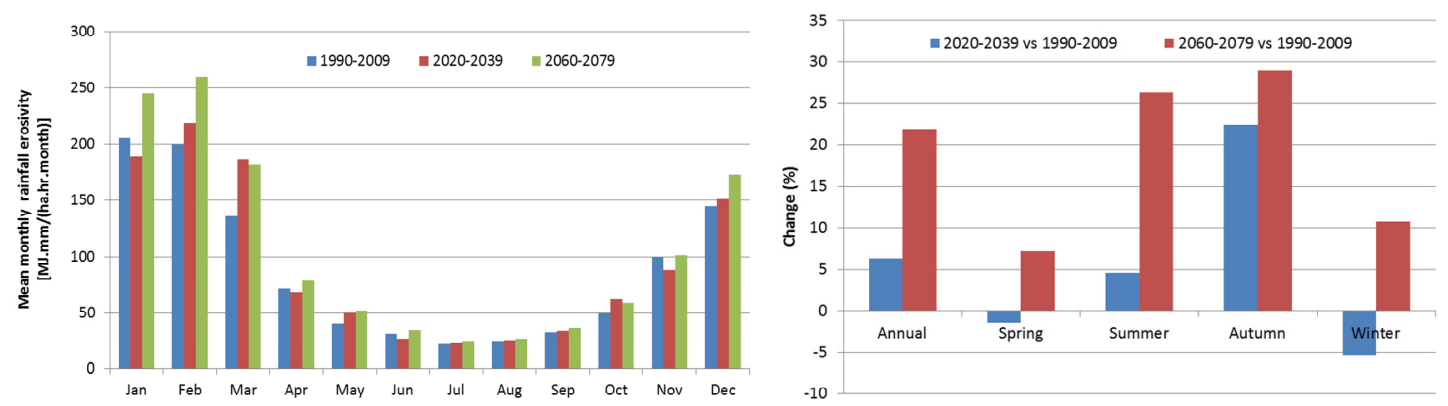

Figure 5. Predicted monthly mean rainfall erosivity (left) and the seasonal change (\%) in two future periods.

The seasonal distribution of rainfall erosivity will have significant impact on hillslope erosion. This implies that when all other RUSLE factors (including K-factor, LS-factor and C-factor) remain unchanged, the seasonality of rainfall erosivity alone could cause about 10 times difference in soil loss even if the rainfall amount and intensity are the same.

Note that the seasonal change is also highly variable across SPRs, ranging from $-12 \%$ in South East and Tablelands in winter to $33 \%$ in Hunter in autumn in the near future. The far future shows more variation ranging from $-18 \%$ in North Coast in winter to $33 \%$ in Far West in autumn. In general, NSW Coast is predicted to experience more change in the next 60 years, in particular Central Coast and North Coast in winter.

\section{CONCLUSION AND FURTHER STUDIES}

NARCliM projected daily rainfall data have been used to predict rainfall erosivity and hillslope erosion risk and their future changes across NSW and SEA. Overall, rainfall erosivity and hillslope erosion risk across NSW in the near future (2020-2039) are predicted to increase about $7 \%$, and about $19 \%$ in the next 50 years. The change is highly variable in space and in time, and the spatial and temporal patterns provide meaningful information for climate change assessment and adaptation. Rainfall erosivity and hillslope erosion are mostly greater in summer than those in other seasons. This suggests that summer (particularly February) is the critical season for hillslope erosion prevention and management. The 7-19\% extra hillslope erosion in the future for unprotected soil is a serious concern. Review of erosion and sediment control standards for construction and re-assessment of land management practices may be required for the predicted high risk areas.

The improved daily rainfall erosivity model performed well and the overall model efficiency $\left(E_{c}\right)$ for estimated rainfall erosivity values is greater than 0.97 with an overall bias slightly over 1 . The set of regional relationships for model parameters are highly recommended for use for NSW and SEA to estimate and map rainfall erosivity and its spatial and seasonal distribution.

The model outputs are available at high temporal and spatial resolution for use in climate impacts assessment and hillslope erosion monitoring for the past, current and future. The time-series rainfall erosivity and hillslope erosion GIS layers in such a high spatial $(100 \mathrm{~m})$ and temporal (monthly to annual) resolution across SEA are first available in Australia. Baseline rainfall erosivity layers for the period of climate normals (1961-1990), a recent (1990-2009) and a longer baseline period (1910-2013) have been produced for better climate change comparisons.

This study has demonstrated an appropriate approach for modelling and mapping monthly and annual rainfall erosivity from daily rainfall data for SEA which is also readily applicable to other regions. The methods have been successfully implemented in GIS for efficient calculation and mapping of the spatial and temporal variation of rainfall erosivity and hillslope erosion across SEA. With the automated GIS process developed in this study, the erosivity maps and erosion modelling can be readily upgraded when better rainfall data and models become available. The spatial interpolation greatly enhanced the level of detail which is useful for assessing erosion hazard and determining the timing of erosion control practices. The time series of high 
resolution rainfall erosivity and hillslope erosion maps can provide detailed information for climate (rainfall) impact assessment, and cost-effective means for hillslope erosion hazard identification and rehabilitation.

Further work will include examining and predicting the impacts of rainfall extremes on rainfall erosivity and hillslope erosion as soil erosion happens mostly during a few severe storm or extreme events. These will provide more useful information for storm impacts on bushfire affected areas so that one can optimise appropriate remedial activities for individual storm events.

\section{ACKNOWLEDGEMENTS}

This project was funded by the NSW Government and managed through the NSW Office of Environment and Heritage $(\mathrm{OEH})$. Many OEH staff from the Climate Science, Soil Science, and Climate Impacts \& Adaptation programs, contributed to this project and their effort is greatly appreciated. Ian Macadam, Terry Koen and John Young kindly provided R scripts for easy handling of the modelling outcomes and charts. Hamish Clark, Yvonne Scorgie and Polly Mitchell reviewed the report and provided useful comments and suggestions. The NARCliM team from the University of New South Wales provided the bias-corrected rainfall projections. All the support and assistance are greatly appreciated.

\section{REFERENCES}

Evans, J.P., Ji, F., Lee, C., Smith, P., Argüeso, D. and Fita, L. (2014). Design of a regional climate modelling projection ensemble experiment - NARCliM. Geosci Model Dev, 7(2), 621-629.

Hutchinson, M.F. (1998). Interpolation of rainfall data with thin plate smoothing splines-part I: two dimensional smoothing of data with short range correlation. Journal of Geographic Information and Decision Analysis, 2, 139-151.

Lu, H. and Yu, B. (2002). Spatial and seasonal distribution of rainfall erosivity in Australia. Australian Journal of Soil Research, 40, 887-901.

Lu, H., Prosser, I.P., Moran, C.J., Gallant, J.C., Priestly, G., Stevenson, J.G. (2003). Predicting sheetwash and rill erosion over Australian continent. Australian Journal of Soil Research, 41(6), 1037-1062.

Nash, J.E. and Sutcliffe, J.V. (1970). River flow forecasting through conceptual models, Part 1: A discussion of principles. Journal of Hydrology, 10, 282-290.

NSW Rural Fire Services (2006) http://www.rfs.nsw.gov.au/ data/assets/pdf file/0014/24332/Bush-FireEnvironmental-Assessment-Code.pdf (accessed 20 July 2015).

Renard, K.G., Foster, G.R., Weesies, G.A., McCool, D.K. and Yoder, D.C. (1997). Predicting hillslope erosion by water: a guide to conservation planning with the Revised Universal Soil Loss Equation (RUSLE). Agricultural Handbook, vol. 703. US Department of Agriculture, Washington DC, pp. 1-251.

Rosewell, C.J. and Turner, J.B. (1992). Rainfall erosivity in NSW. CaLM Technical Report No. 20, New South Wales Department of Conservation and Land Management, Sydney.

Wischmeier, W.H. and Smith, D.D. (1978). Predicting rainfall erosion losses, a guide to conservation planning. Agricultural Handbook, vol. 537. US Department of Agriculture, Washington, DC. 58 pp.

Yang, X. and Yu, B. (2015). Modelling and mapping rainfall erosivity in New South Wales, Australia. Soil Research, 53, 178-189.

Yang, X. (2015). Digital mapping of RUSLE slope length and steepness factor across New South Wales. Soil Research, 53, 216-225.

Yang, X., Yu, B. and Xie, X. (2015). Predicting changes of rainfall erosivity and hillslope erosion risk across Greater Sydney Region, Australia. International Journal of Geospatial and Environmental Research (Open access htt://dc.uwm.edu/ijger/vol2/iss1/2).

Yu, B. and Rosewell, C.J. (1996). An assessment of a daily rainfall erosivity model for New South Wales. Australian Journal of Soil Research, 34, 139-152.

Yu, B. (1998). Rainfall erosivity and its estimation for Australia's tropics. Australian Journal of Soil Research, 36, 143-165. 